\title{
IS FORCING THEM WORTH THE EFFORT? BENEFITS OF MANDATORY INTERNSHIPS FOR GRADUATES FROM DIVERSE FAMILY BACKGROUNDS AT LABOUR MARKET ENTRY
}

\author{
Markus Klein and Felix Weiss \\ Mannheim Centre for European Social Research (MZES), University of \\ Mannheim
}

\begin{abstract}
Mandatory internships are implemented into higher education curricula in order to ease the labour market integration of graduates. This article evaluates the utility of mandatory internships in Germany by assessing the effect on graduates' transition from higher education to work. We examine whether these compulsory programs provide extra benefits for graduates from families with lower educational background. Three different outcome variables are used to characterize the labour market entry: search duration until the first significant job, employment history complexity and wages five years after graduation. Our results clearly indicate that compulsory internship programs neither have a positive effect on labour market outcomes in general nor are they particularly beneficial for graduates from lower educational background.

Key words: Internships, Transition from Education to Work, Job Training Program, Germany
\end{abstract}

Word count: 8163 


\section{Introduction}

Mandatory internships or "sandwich placements" have become a substantial element of curricula in Germany's system of higher education. For instance, a survey among students enrolled in higher education in Germany shows that $55 \%$ of the respondents took part in an internship within the last 12 months. Two thirds of these internships were compulsory (e.g. Krawietz, Müßig-Trapp \& Willige, 2006) and in all European countries a substantial share of students participates in such work placements (Allen, 2007). Practical experience is presumed to enhance employability and to ease the entrance into the professional world and, as a result, students are instructed to invest time, effort and sometimes even money into work experience during their studies. From a policy perspective, it is important to know to what extent the introduction of mandatory internships into curricula influences the process of labour market integration. Internships present an opportunity cost of either less time for instruction in class or a delayed entry into the labour market. Several theories suggest that early labour force experience has a positive effect on a smooth transition from higher education to work. Not only is it an opportunity to establish social ties with employers and employees but it also enables students to learn about the requirements of specific jobs and adapt to a working environment. At the same time, employers have the opportunity to "screen" future graduates on the basis of everyday performance.

The implementation of compulsory internship programs may additionally have a positive impact on social fluidity. Recent research shows that lower class children tend to enrol less often in tertiary education than children from privileged classes (Shavit et al., 2007). One hypothesis to explain these findings is that upper class children have access to more resources that are relevant for a successful educational career (Erikson \& Jonsson, 1996). Beyond these educational disparities social class origin still has a direct impact on labour market outcomes (Jackson, Goldthorpe \& Mills, 2005). Thus, class-specific differences in early labour market success are not only mediated through educational achievement or 
human capital but also through other mechanisms such as a different availability of cultural or social resources (Breen, 1998: 292; Hansen, 2001: 212). Even when they achieve the same educational level, children from different class or educational origin arrive at different destinations in the labour market. As higher education graduates from lower educational backgrounds lack parental social resources, they may have more difficulties in entering the labour market than their peers whose parents have greater social networks. The implementation of mandatory internships in higher education curricula could be a way to help them gaining access to social networks and thus reduce their disadvantages at labour market entry. Thus, we examine whether mandatory internships particularly improve the labour market integration of graduates from lower educational background.

Most studies evaluating the impact of internships on labour market entry concentrate on voluntary rather than mandatory internships. There are two key reasons to focus on compulsory programs. First, the evaluation of mandatory internships is policy relevant and has a clear policy implication. In order to assess the policy of forcing students into a "real" working environment before graduation one should not refer to the effect of voluntary internships. Voluntary internship experiences may differ from mandatory ones e.g. in length or by selection effects whereby only the most impressive students participate, who would likely have better job opportunities even without the potential benefit an internship might provide. Observable or unobservable differences between students lead to our second, more methodological, motivation to assess the impact of mandatory programs. If students who voluntarily participate in an internship differ from their non-participating peers in certain characteristics that are valuable for a successful career-start, the effects found for internships on early labour market outcomes are biased. Some studies address these issues with statistical controls (Allen \& van der Velden, 2007; Fuller \& Schoenberger, 1991; Kreuter, 2000; Schröder, 2002) while others ignore it and solely examine correlations (Bowes \& Harvey, 1999; Richards, 1984). The fact that mandatory internships are not optional for students in a 
certain study program considerably ameliorates the problem of selection bias in our analysis. Once students have chosen to study in a program that requires participation, selective decisions for internships are not possible. We are left with (smaller) problems that stem from self-selection of students into certain study programs that offer mandatory internships or not and the varying labour market outcomes of these programs.

In this article we examine the impact of early labour force experience in terms of mandatory internships on graduates' transition from school to work. In order to assess the success of labour market integration we look at the duration of job search for the first significant employment, the employment stability in the first five years after graduation and the hourly wages five years after graduation. The remaining selectivity problems on the level of institutions and study programs and on the individual level of selection into programs will be addressed by propensity score matching.

\section{The implementation of mandatory internships in the German higher education system}

The implementation of mandatory internships varies not only between higher education institutions but also between study programs within each institution. Thus, it is not the case that a university or Fachhochschule (university of applied sciences) automatically introduces compulsory internship for all programs of study. In order to give an illustration of typical modes of implementation, we consulted the curricula for the social sciences and business/economics described on the homepages of several German universities. In most study programs the duration of mandatory internships is at least three months. In some second-tier practically oriented Fachhochschulen the duration is six to twelve months. Full universities tend to require shorter internships than Fachhochschulen. Often, the student is obliged to find an employer him- or herself. Some institutions have arrangements with employers or provide an internship manager who places students into internships or gives advice. 


\section{Theoretical background}

\section{Labour market entry and the value of early labour force experience}

Policy-makers and the management of higher education institutions introduce mandatory internships into curricula in order to better prepare students for the "real" world of work (Ryan, Toohey \& Hughes, 1996). From an academic perspective, several theoretical arguments indeed suggest positive effects of early work experience such as mandatory internships on the transition from higher education to work. One argument is that graduates who complete an internship acquire occupation-specific skills that are related to their field of study (Sarcletti, 2007; Scholz, Steiner \& Hansmann, 2004). This raises their productivity level in future jobs being directly rewarded by employers with higher wages. Similar, one could propose that work experience before graduation equips students with specific forms of cultural capital. Beyond learning how to perform better and more efficient on a job, interns also acquire cultural codes and get used to specific manners or soft skills that are prevailing in the social environment of a certain industry sector, company, or occupation. Most of these skills are not communicated in the educational system (Jackson et al., 2005) and must be experienced elsewhere (home environment, on-the-job).

Whereas student involvement in the workplace enables employers to screen potential employees (Stiglitz, 1975), this also enables students to screen potential working environments and job opportunities. Prospective employers may also value letters of recommendation, commonly issued at the end of jobs or internships, as signals for graduates' potential productivity (Spence, 1973). Hence, doing an internship should facilitate a faster and smoother match between employer and employee as it increases the knowledge about the contracting partner on both sides (Sørensen \& Kalleberg, 1981). In an experimental simulation Taylor (1988) found that students with an internship experience are evaluated as 
being significantly more qualified and hence have a higher probability of being hired than students without internships.

In addition, social networking with potential employers and employees may facilitate students' job search process after graduation (Granovetter, 1974). Internships provide a bridge experience to ease the transition between "student" and "employee" status. By allowing student to shift contexts from the classroom to the workplace students are able to gain access to informal networks with highly valuable resources for the future job search process. Several studies on firms' hiring behaviour come to the conclusion that applicants being referred by current employees have a higher probability of being hired than non-referrals (Fernandez, Castilla \& Moore, 2000; Fernandez \& Weinberg, 1997; Petersen, Saporta \& Seidel, 2000). As people in business networks not only share information about job vacancies but also many aspects of job quality such as wages, promotion prospects or working conditions, the enhanced social capital should reduce the job search duration and improve the match between a graduate and his or her first significant job.

In summary, most theoretical considerations discussed here consistently expect that (mandatory) internships before graduation will ease the transition from higher education to work.

\section{Social origin and labour market entry}

Beyond a general impact of mandatory internships we ask if these benefits are particularly important for students from families with lower parental educational attainment. While most of the aforementioned advantages are expected to be enhanced by internship experiences they are also assumed to be distributed unequally across different social backgrounds. In our sample, however, the students are homogenous with regard to formal educational achievement. Thus, as long as we assume that skills are acquired through formal education, there should be no differences between students with higher and lower educational background in the amount of occupation-specific skills. However, it is plausible that students 
coming from higher educated families use parental social capital more often to partake in (advantageous) voluntary internships. This circumstance might result in an advance in jobspecific skills.

Parental education, occupation or class should rather shape the distribution of cultural capital. In particular, if students from more privileged family backgrounds enter the same occupations as their parents (Jonsson et al., 2009), they may benefit from parental knowledge about occupation-specific cultural and behavioural codes even before entering their studies. In contrast, students from families with lower parental educational attainment have to rely on later experiences. Internship programs during studies may give them the opportunity to overcome this disadvantage.

With regard to social capital it is very plausible that disparities between social background groups exist. It can be expected that parental social capital beneficial on the labour market for tertiary graduates is more easily available in higher educated families (Burt, 1983; Lin, Ensel \& Vaughn, 1981). In fact, differences in social capital are assumed to be one of the reasons that lower class children invest less in higher education than upper class children (Erikson \& Jonsson, 1996: 30). Thus, one can assume that in particular students from lower educational background benefit from the acquisition of their "own" social capital through mandatory internships.

All in all, the social capital perspective suggests that mandatory internships are more beneficial for graduates coming from less educated families and thus lead to an amelioration of disadvantages from social origin.

\section{Operationalisation of the labour market entry}

We operationalise the labour market integration process using three different outcomes that capture different aspects of labour market success: duration of job search 
before the first significant employment spell, the "complexity" of labour market careers during the first five years after graduation and log hourly wages five years after graduation.

Job search duration is often seen as an indicator for a successful and smooth transition from school to work (Teichler, 2000: 12). The search time is measured as the period between the month of final degree attainment and the beginning month of the first reported significant employment spell. A job is defined as significant if an individual's early work biography displays "dependent employment" for the first time. We took care to distinguish these employment spells from short-term stop-gap jobs and marginal employments (all kinds of minor or casual work such as summer jobs or internships). Whereas the episodes "unemployed", “freelance work", “to job", “internship", “advanced training" and "family work" are counted as search time, "miscellaneous" or "parental leave" are not considered as active search time and therefore not counted as such. There are 47 cases which do enter any job throughout the whole observation period. Excluding them from our analysis does not change the results.

Complexity of employment history in the first five years after graduation represents an indicator for the quality of the matching between the job and the applicant. The risk of a job mismatch is particularly high for recent graduates as employers only have few signals that indicate the prospective performance of the applicant and graduates lack sufficient information about employers and job characteristics (Wolbers, 2003). As outlined in our theoretical discussion, early work experience may improve the match between employer and employee in the first significant job and thus leads to more stability in the early labour market career. We measure the complexity of the transition from higher education to work as suggested by Elzinga (in press). A more comprehensive discussion of methodological options is also found in a recent working paper of Aisenbrey and Fasang (2009). In this framework labour market careers are seen as sequences of distinct activities or states, such as "employment" or "unemployment". Each of these sequences can be divided into different 
sub-sequences. Sub-sequences are sequence patterns describing parts of the labour market career. Consider for example a sequence of "internship"-“unemployment”-“employed”, then "unemployed"-“employed" is a possible sub-sequence. The criterion for complexity of a career is the logarithm to the basis 2 of the number of distinct sub-sequences. The complete sequence of labour market statuses is divided into all possible sub-sequences that are contained in it. The more different activities a career involves and the more transitions between activities occur, the more sub-sequences can be found. Beyond that, this measure also captures the number of transitions between two identical activities. If identical activities are "located" closer to each other in the career, this reduces the number of possible subsequences. The logarithm is chosen as a more preferable scale for practical research than the original number of sub-sequences following the suggestion of Elzinga (in press). In fact, as we distinguish many different states, the number of sub-sequences inflates and would create very large numbers if we would not adopt this practice. If two states are parallel, we must define one of them as the dominant activity. Therefore we introduced the following hierarchical order: "in higher education" > "employed" > "self employed" > "internship" > "unemployed" > "dissertation" > "minor work" > "housework/family" > "further education" $>$ "miscellaneous". For example, a person who reenrols into university is counted as student, even if he/she follows a side job, since studying takes a higher position in our dominance structure.

The logarithm of the hourly wage is used as a measure of job quality: Beyond finding a job at all, the quality of the achieved job might differ substantially. Again, we assume that a better match between applicant and job increases the productivity and subsequently the salary of the graduates (Garcia-Espejo \& Ibánez, 2006; van de Werfhorst, 2002). The logarithm is used for two reasons. First, differences between high wages that are large in absolute terms but substantively meaningless are weighted as less important than the same differences between lower wages. For instance, a difference of $€ 500.00$ is a substantive difference for 
low-wage earners, but not for the highest $5 \%$ of the wage distribution. Second, it makes our measure less susceptible to outliers. As entry-level jobs in a company rarely mirror the quality of the position in pay, we use the gross wage five years after graduation as a long term indicator, additionally including annual bonuses.

\section{Data and methods}

For the purpose of this study, we consider a cohort of graduates from higher education in Germany, surveyed in the HIS (Hochschul-Informations-System) Graduate Panel 1997 (Fabian \& Minks, 2006). 6216 respondents were asked in a mail survey one and five years after graduation and reported their full employment history for the first five years. Graduates of fields that acquire a "Staatsexamen"-degree, which is the standardized governmentrecognized degree for medical doctors, veterinaries, clerics, lawyers, pharmacists and teachers throughout Germany, usually do not compete directly on the labour market. Their curricula include a traineeship phase (similar to mandatory internships) after graduation for all students and in all study programs in Germany and at the same time institutionalized arrangements for the transition into work. This parallel occurrence of traineeships and government organized transition to work could easily bias our analyses, therefore we exclude these cases. Moreover, we exclude fields of study that mainly or fully lack variation in the implementation of mandatory internships across higher education institutions. Counterfactual analysis requires a substantial degree of randomness in order to have people with identical characteristics observed in both treatment and control state (Caliendo \& Kopeinig, 2008: 38). Specifically, those fields where $85 \%$ or more of the graduate sample within a field complete mandatory internships were excluded. A detailed description of included fields of study is given in table 1. Small changes in the threshold level do not alter the results. Overall, this reduces our sample to 2594 cases. 


\section{Table 1 about here}

In observational studies the estimator for the effect of internships could be biased due to a non-random assignment of students to those participating and those not participating in internship experiences. By using compulsory internships instead of voluntary ones we substantially reduce the number of potential confounding factors, as students are not able to self-select into participation once enrolled in a certain program. However, it is still possible that there is self-selection into different fields of study or higher education institutions which require more or less compulsory internships. Thus, students who participate in mandatory internships may not be similar on average to those not participating. In order to take this into account and approach an estimation of the unbiased effect of mandatory internships on our three outcomes, we use the propensity score matching-technique (PSM, Leuven \& Sianesi, 2003; Rosenbaum \& Rubin, 1983). Here we match cases on characteristics of the study program and on individual characteristics that could potentially select certain students into different study programs. To ensure the comparability between graduates that are used for matching, we estimate propensity scores measuring the propensity to partake in study programs encompassing a mandatory internship. In our case this assignment model is estimated using a logistic regression model. Technically, the propensity score is defined as the probability of participating in a mandatory internship, conditional on students' characteristics before enrolling (cf. Rosenbaum \& Rubin, 1983). In a second step we match graduates with and without mandatory internship based on the propensity score using the Kernel Matching Method (Heckman, Ichimura \& Todd, 1998). This method matches each individual with mandatory internship to the weighted average of all those individuals who could decide themselves about participation in an internship. A major advantage of this approach compared to other matching methods is a higher precision of the estimates as more information is used. However, the estimation might be more susceptible to bias due to the possible usage of bad 
matches. As the choice of a matching estimator is to some degree arbitrary, we replicated our results using "Nearest-Neighbor"-, "Radius"- and "Stratified" Matching (Becker \& Ichino, 2002). None of the matching algorithms changed the substantive conclusion of our findings. Therefore, we only report the results of the kernel matching. According to a test suggested by Becker and Ichino (2002) our assignment models satisfy the balancing property. The balancing property is satisfied if the background characteristics of the individuals with mandatory internships are properly adjusted to the ones without. The criterion for a significant violation of the balancing hypothesis was set to the level 0.001 .

For the analysis stratified by parental education, we distinguish between high and low educational background. The "high"-category contains all graduates who have at least one parent with a tertiary degree, all other graduates are classified into the "low"-category.

\section{Results}

First, we estimate the propensity score in a binary regression model with "having mandatory internship" as the dependent variable. Our assignment models use a rich set of variables that are either related to the characteristics of study programs or to characteristics of individuals that influence their choice of study programs. Most importantly, we include the field of study, type of institution (first tier universities vs. second tier Fachhochschulen) and characteristics of the study environment as well as the federal state of the institution in the estimation. Although particularly in the pre-Bologna-era the German university system was highly standardized, where no elite universities exist, we control for items (self-assessment of students) such as degree of structuring or how up-to-date the acquired methods are to take account of potential differences in the quality of institutions and study programs that may influence the propensity of introducing mandatory internships and the labour market outcomes at the same time. We argue that this captures the variation in the implementation of 
mandatory internships between fields and institutional settings and their independent effects on labour market outcomes well. An exemplary assignment model is given in table 2 .

Table 2 about here.

For each outcome we have three assignment models covering the full model and the models stratified by educational background. Thus, overall we have nine assignment models. Due to space restrictions, the other eight assignment models are available in an onlineappendix at http://www.mzes.uni-mannheim.de/publications/misc/appendix_kleinweiss.pdf. We assume that the introduction of mandatory internships into curricula within a certain study program is arbitrary and rather unrelated to other (unobserved) characteristics that are relevant for the successful integration into the labour market. Additionally, we propose that individual decisions to opt for a certain study program do not directly depend on the availability of mandatory internships. Instead of choosing a study program with mandatory internship students can easily choose to study in a different program and partake in a voluntary internship. Therefore, we argue that our assignment models indeed guarantee to a high degree that individuals with and without mandatory internship are similar.

First, we compare the unmatched means for each outcome variable of participants and non-participants in mandatory internships. Second, we report the average treatment effect on the treated (ATT) based on the matched propensity scores. Table 1 shows both values for the three outcome variables job search duration, complexity of the employment career and log hourly wages.

Starting with the impact of mandatory internships on the job search duration, we find a search time bonus of 1.4 months for participants under the unmatched condition. A t-value of -3.43 indicates that this difference is statistically significant at conventional criteria. However, comparing individuals with and without mandatory internship under the matched condition, 
the group difference (ATT) is close to zero. Further, it is not statistically significant as indicated by the respective z-value. Thus, completing a mandatory internship seems to have no benefit with regard to job search duration. The same pattern can be seen for our second outcome "complexity" of employment history: a significant advantage in employment stability for graduates with mandatory internships in comparison to the ones without is not confirmed under the matching condition. Thus, effects of mandatory internships are zero when controlling confounding factors. In the case of hourly wages five years after graduation, we do not even find group differences under the unmatched condition. If any, there is on average even a slight punishment in monetary returns for individuals completing mandatory internships.

For all three indicators of a "smooth" transition into the labour market the impact of mandatory internships is only present as long as we do not account for heterogeneity between individuals with and without mandatory internship. The apparent bias under the unmatched condition is explained by matching treated and untreated graduates being as similar as possible. Thus, we do not find a positive effect of the participation in mandatory internship programs on the labour market integration of tertiary graduates.

Table 3 about here.

As the field of study has a strong impact on the treatment in the assignment model, it might be better to perform the matching separately (or stratified) by field of study (Heckman, Ichimura \& Todd, 1997). Due to small sample sizes we are unable to split our sample to fields on a very detailed level so we applied a stratified matching to four broader field groups: "Business and Economics", "Technical fields and Agriculture", "Sciences and Mathematics" and "Arts and Social Sciences". As the field-specific effects do not differ substantially from 
the overall group difference (ATT), the stratified matching does not alter our evaluation of mandatory internships.

Our second hypothesis proposed that graduates with parents that did not attend university benefit disproportionately from mandatory internships than those with parents who did. In order to test this, table 1 additionally indicates the unmatched and matched differences between graduates with and without mandatory internships separately by parental educational attainment. For both groups of educational background the unmatched differences between participants and non-participants are nearly identical with the overall differences. The ATT for compulsory internship programs shows no significant difference under both conditions whatever degree the parents have.

Under the matched condition graduates from lower educational background with mandatory internships still have a slightly but not significantly shorter search time $(0.26$ months less) than their peers without mandatory internships. Among students with higher educational background the ones with mandatory internships even search longer ( 0.25 months more) than the ones without. Although the effects are in the assumed direction, the nonsignificant effects do not support our second hypothesis.

The same pattern applies to complexity of work history. While graduates from a higher educational background in the mandatory internship group have more complex employment patterns than graduates from the same background but without this internship, there remains a small positive effect of mandatory internships on job stability for graduates from less educated families under the matched condition. However, the analytic z-value of 0.57 indicates that the effect of mandatory internships is not significant for graduates from lower educational background. Thus, hypothesis 2 is not supported with regard to this outcome as well.

Regarding the log hourly wages, we find a negative ATT of mandatory internships for both graduates with and without academic parents. While this negative effect is close to zero 
for graduates from higher educational background under the matched condition, a remarkable but not significant negative ATT of $6.3 \%$ lower wages for graduates with low educational background prevails.

To sum up, there is no evidence for either hypothesis: Neither can mandatory internships ease the transition from higher education to work on average, nor do they prove to be particularly helpful for students from less educated families in mediating disproportionate benefits from familial social networks or cultural capital. However, the rejection of our second hypothesis does not rule out theories that expect lower class families to have a less smooth transition from higher education to work due to lack in beneficial resources. Hence, the implementation of mandatory internships is not able to mitigate family background effects on labour market outcomes.

\section{Discussion and Conclusion}

At the outset of this article we introduced two different research objectives, both regarding the implementation of compulsory internships in tertiary curricula. First, we intended to test theories that claim early work experience to have a beneficial effect on the labour market integration of tertiary graduates. Our second purpose was to evaluate the practical utility of introducing mandatory internships into higher education curricula and its implication for policy makers. Beyond that we were interested in the question whether particularly graduates from families with lower parental educational attainment benefit from mandatory internships. In order to measure the smoothness of the transition from higher education to work we considered three different aspects: the job search duration for the first significant job, the "complexity" of the employment career and log hourly wages five years after graduation. We estimated outcome differences between students who were obliged to participate in internships and those who were free in their choice. Accounting for observed differences between students in programs with and without compulsory internship we 
corrected the estimation of treatment effects using propensity score matching. Moreover, the use of mandatory internships that force all students in a certain study program at a certain institution to partake in an internship enables us to reduce biased effects due to unobserved heterogeneity in ability or motivation.

Our results are clear-cut with regard to policy evaluation. Even though the literature provides evidence for beneficial effects of internships in general, we do not find an effect of compulsory internship programs on labour market outcomes. Furthermore, we do not find any evidence that these programs are useful to ameliorate disadvantages in labour market integration for graduates from lower educational background. Therefore, the value of compulsory internship programs is clearly called into question. One possible explanation for our findings would be to reject the proposed theoretical mechanisms themselves. This would be in strong contradiction for instance to findings on the impact of social capital on labour market outcomes in general (Flap \& Boxman, 2001). There might be different reasons for this contradiction between our findings and previous research on voluntary internships or other early labour force experience.

First, one could argue that students lack motivation when being obliged to do an internship. The compulsory nature of these internships may lead to lower job performance and consequently to a smaller gain in occupation-specific skills throughout their work experience. Research in social psychology showed that the introduction of extrinsic motivation can reduce intrinsic motivation (Deci \& Moller, 2005) and hence students could be less motivated to learn and to take an active role in the internship. While voluntary internships can be regarded at least to some degree as intrinsically motivated, making it a compulsory requirement clearly introduces extrinsic motivation.

Second, internships do not automatically have positive effects for all students. Only interns with high abilities may acquire sufficient job-specific knowledge and gain access to additional resources, whereas their less able peers may even be negatively evaluated by 
employers. On average, these positive and negative impacts might cancel each other out and finally result in the fact that committing all students to complete an internship programs does not proof to be beneficial.

Third, from the perspective of signalling theory (Spence, 1973), mandatory internships may not work as meaningful signals in addition to other signals on the labour market and therefore employers do not rely on them. This may be due to the fact that their signalling value is blurred by high participation rates of students in voluntary internships or other early work experiences.

Fourth, it seems plausible that only students who are motivated or highly able select into voluntary internships. This problem is commonly called "selection problem in the social sciences" (Manski, 1995). Due to their characteristics these graduates would be successful on the labour market even without participating in an internship. Thus, the absence of an effect of mandatory internships may indicate that the positive impact of voluntary ones or other fieldspecific work experience (e.g. Franzen \& Hecken, 2002: 746) on later career outcomes may possibly appear due to unobserved heterogeneity in ability, motivation or effort of students.

Fifth, another reason for differences in the impact of mandatory and voluntary internships could be that mandatory programs are not capable to provide graduates with additional resources that are theoretically expected and help to ease the transition into work. As the length of mandatory programs is set by the school, their low value could be due to the shorter duration in comparison to voluntary programs. A disadvantage of our study is that we only know whether graduates were required to do an internship or not. Hence, we neither have information on the search process for compulsory internships nor about the content and duration of these programs. Limiting the examination to those who participated in mandatory internships for a length of six months and more could possibly change the results in a more beneficial direction. Concerning practical relevance, our general conclusion that the current implementation misses the target of imparting better employability is not affected. 
Given the advantageous setting for "causal" analysis we intended to provide strong evidence for common assumptions from social science theories. However, these theoretical considerations turned out not to be predictive in the case of completing an internship. To summarize, we suggest that this is not due to the fact that the theories are wrong. In our opinion, the reason is that the mandatory nature of the internship may cancel out potential benefits.

As a methodological note, we want to stress the importance of field of study (see table 2) as confounding factor, which has to be taken into account when examining the effect of internships or other additional qualifications on labour market integration. Much of the effect of mandatory internships is explained by this variable and their independent effect on the transition from school to work. Hence, future studies that assess the effect of school-to-work programs, internships or any other kind of work experience before graduation are strongly advised to consider the horizontal dimension of educational stratification.

Consequently, one could also argue that the "success" of mandatory internships in enhancing employability depends on the existence of occupation-specific school to work channels. In liberal arts programs without an institutional link to concrete occupations (e.g. the German Magister Artium), the implementation of mandatory internships may be more beneficial than in fields with more established channels into the workforce. However, when stratifying our matching by field of study, the results are replicated for all broader field groups. Although we cannot ensure that our categorization of fields of study is detailed enough, this suggests that mandatory internships do not even add anything beneficial to students' labour market integration even in those fields with generally more problematic transitions into employment.

Finally, additional attention should be given to the type and quality of mandatory internship programs. Not being able to differentiate between different mandatory internships can certainly be seen as a limitation of our data. Further evaluation of other related 
institutional setups in higher education such as "internship managers" helping students to find an appropriate internship should be conducted. It should also be noted that these results do not necessarily question the utility of internships per se, but rather the policy of implementing mandatory internships into curricula. With respect to processes at labour market entry, other institutional settings of the education-labour market linkage specific to Germany might produce different findings than we would see in other countries. Beyond institutional settings, cultural differences and academic traditions vary considerably between countries and may influence the whole transition from higher education to work. To elaborate more on these contextual effects, an international comparison with regard to our question would certainly be of interest. As our results are limited to the German context, these questions have to be left open to further research.

Acknowledgements: Stimulating discussions with Anne Kronberg are gratefully acknowledged. Furthermore, we would like to thank Christi M. Smith and anonymous reviewers of this journal for valuable and constructive comments. Marianne Schneider, Hanna-Marei Steininger, Maren Albrecht and Mirte Scholten were a great help in preparing the manuscript. This research was supported by grants of the German Science Foundation (DFG) and the Baden-Württemberg Foundation. 


\section{References}

Aisenbrey, S. \& Fasang, A. E. (2009) New life for old ideas: The 'second wave' of sequence analysis - bringing the "course" ack into the life course. Report for Yale University (New Haven).

Allen, J. (2007) Mobilization of human resources. Chapter 5 in: The flexible professional in the knowledge society. General results of the reflex project. Report for Research Centre for Education and the Labour Market, Maastricht University (Maastricht).

Allen, J. \& Van Der Velden, R. (2007) Reflex - the flexible professional in the knowledge society: General results of the reflex project. Report for Research Centre for Education and the Labour Market, Maastricht University (Maastricht).

Becker, S. O. \& Ichino, A. (2002) Estimation of average treatment effects based on propensity scores. The Stata Journal, 2(4), 358-377.

Bowes, L. \& Harvey, L. (1999) The impact of sandwich education on the activities of graduates six months post-graduation. Report for Centre of Research into Quality (Birmingham).

Breen, R. (1998) The persistence of class origin inequalities among school leavers in the republic of ireland, 1984-1993. British Journal of Sociology, 49, 275-298.

Burt, R. S. (1983) Range, in: R. S. Burt (Ed.) Applied network analysis : A methodological introduction. (Beverly Hills, CA, Sage), 264-296.

Caliendo, M. \& Kopeinig, S. (2008) Some practical guidance for the implementation of propensity score matching. Journal of Economic Surveys, 22(1), 31-72.

Deci, E. L. \& Moller, A. C. (2005) The concept of competence - a starting place for understanding instrinsic motivation and self-determined extrinsic motivation, in: A. J. Elliott \& C. S. Dweck (Eds) Handbook of competence and motivation. (New York, The Guilford Press), 579-597.

Elzinga, C. H. (in press) Complexity of categorical time series. Sociological Methods and Research.

Erikson, R. \& Jonsson, J. O. (1996) Explaining class inequality: The swedish test case, in: R. Erikson \& J. O. Jonsson (Eds) Can education be equalized? The swedish case in comparative perspective. (Boulder, Colorado, Westview Press), 1-64.

Fabian, G. \& Minks, K.-H. (2006) Dokumentation des Scientific Use Files "HisAbsolventenpanel 1997". Report for Hochschul Informations System (Hannover).

Fernandez, R. M., Castilla, E. J. \& Moore, P. (2000) Social capital at work: Networks and employment at a phone center. American Journal of Sociology, 105, 1288-1356.

Fernandez, R. M. \& Weinberg, N. (1997) Sifting and sorting: Personal contacts and hiring in a retail bank American Sociological Review, 62(6), 883-902

Flap, H. \& Boxman, E. (2001) Getting started: The influence of social capital on the occupational career in: N. Lin, K. Cook \& R. S. Burt (Eds) Social capital - theory and research. (New York, Transaction Publishers), 159-181.

Franzen, A. \& Hecken, A. E. (2002) Studienmotivation, Erwerbspartizipation und der Einstieg in den Arbeitsmarkt. Kölner Zeitschrift für Soziologie und Sozialpsychologie 54(4), 733-752.

Fuller, R. \& Schoenberger, R. (1991) The gender salary gap: Do academic achievement, internship experience, and college major make a difference? Social Science Quarterly, 72(4), 715-726.

Garcia-Espejo, I. \& Ibánez, M. (2006) Educational-skill matches and labour achievements among graduates in spain. European Sociological Review, 22, 141-156.

Granovetter, M. S. (1974) Getting a job. A study of contacts and careers, (Cambridge, Havard University Press). 
Hansen, M. N. (2001) Education and economic rewards: Variations by social-class origin and income measures. European Sociological Review, 17(3), 209-231.

Heckman, J. J., Ichimura, H. \& Todd, P. (1997) Matching as an econometric evaluation estimator: Evidence from evaluating a job training programme. Review of Economic Studies, 64(3), 605-654.

Heckman, J. J., Ichimura, H. \& Todd, P. (1998) Matching as an econometric evaluation estimator. Review of Economic Studies, 65(2), 261-294.

Jackson, M., Goldthorpe, J. H. \& Mills, C. (2005) Education, employers and class mobility. Research in Social Stratification and Mobility, 23, 3-33.

Jonsson, J. O., Grusky, D. B., Di Carlo, M., Pollak, R. \& Brinton, M. (2009) Micro-class mobility: Social reproduction in four countries. American Journal of Sociology, 114(4), 977-1036.

Krawietz, M., Müßig-Trapp, P. \& Willige, J. (2006) Praktika im Studium. Report for HIS Hochschul Informations System (Hannover).

Kreuter, F. (2000) Abschlußbericht des Forschungsprojekts. Absolventenbefragung des Fachbereichs Politik- und Verwaltungswissenschaft der Universität Konstanz. Report for Universität Konstanz (Konstanz).

Leuven, E. \& Sianesi, B. (2003) Psmatch2: Stata module to perform full mahalanobis and propensity score matching, common support graphing and covariate imbalance testing. Available online at: http://ideas.repec.org/c/boc/bocode/s432001.html (accessed May 22 2009).

Lin, N., Ensel, W. M. \& Vaughn, J. C. (1981) Social resources and strength of ties: Structural factors in occupational status attainment. American Sociological Review, 46(4), 393405.

Manski, C. F. (1995) Identification problems in the social sciences, (Cambridge, Massachusetts, Harvard University Press).

Petersen, T., Saporta, I. \& Seidel, M.-D. L. (2000) Offering a job: Meritocracy and social networks. American Journal of Sociology, 106(3), 763-816.

Richards, E. W. (1984) Undergraduate preparation and early career outcomes: A study of recent college graduates. Journal of Vocational Behavior, 24, 279-304.

Rosenbaum, P. R. \& Rubin, D. B. (1983) The central role of the propensity score in observational studies for causal effects. Biometrika, 70(1), 41-50.

Ryan, G., Toohey, S. \& Hughes, C. (1996) The purpose, value and structure of the practicum in higher education: A literature review. Higher Education, 31(3), 355-377.

Sarcletti, A. (2007) Humankapital und Praktika - Die Bedeutung des Kompetenzerwerbs in Praktika für den Berufseinstieg bei Universitätsabsolventen der Fachrichtung Betriebswirtschaftslehre. Zeitschrift für Erziehungswissenschaft, 10(4), 549-566.

Scholz, R. W., Steiner, R. \& Hansmann, R. (2004) Role of internship in higher education in environmental sciences. Journal of Research in Science Teaching, 41(1), 24-46.

Schröder, J. (2002) Der Berufseinstieg von Universitätsabsolventinnen und-absolventen: Eine empirische Untersuchung anhand der sozialwissenschaftlichen Absolventinnen und Absolventen der Universität Mannheim. Universität Mannheim.

Shavit, Y., Arum, R., Gamoran, A. \& Menahem, G. (Eds.) (2007) Stratification in higher education: A comparative study, (California, Stanford University Press).

Sørensen, A. B. \& Kalleberg, A. L. (1981) An outline of a theory of the matching of persons to jobs, in: I. Berg (Ed.) Sociological perspectives on Labor Markets. (New York, Academic Press).

Spence, M. (1973) Job market signaling. Quarterly Journal of Economics, 87(3), 355-374.

Stiglitz, J. E. (1975) The theory of "screening", education, and the distribution of income. American Economic Review, 65(3), 283-300. 
Taylor, M. S. (1988) Effects of college internship on individual participants. Journal of Applied Psychology, 73(3), 393-401.

Teichler, U. (2000) Potentiale und Erträge von Absolventenstudien, in: A. Burkhardt, H. Schomburg \& U. Teichler (Eds) Hochschulstudium und Beruf - Ergebnisse von Absolventenstudien. (Kassel, Wissenschaftliches Zentrum für Berufs- und Hochschulforschung), 9-26.

Van De Werfhorst, H. G. (2002) Fields of study, acquired skills and the wage benefit from a matching job. Acta Sociologica, 45, 287-303.

Wolbers, M. H. J. (2003) Job mismatches and their labour-market effects among schoolleavers in europe. European Sociological Review, 19(3), 249-266. 
Table 1: Criteria of selecting fields of study into the sample: Degree of implementation of mandatory internships into curricula and "Staatsexamen" degree

1 included in sample

${ }^{2}$ not included in sample due to a share of non-implementation of mandatory internship $<15 \%$ or "StaatsexamenDegree"

Field of study
Freq. $\begin{array}{cc}\begin{array}{c}\text { Share mand. int. } \\ \text { implemented }\end{array} & \begin{array}{c}\text { Staatsexamen" } \\ \text { degree }\end{array}\end{array}$

\begin{tabular}{|c|c|c|c|}
\hline agricultural economics, nutritional science, $\mathbf{F H}^{*}$ & 70 & $.67^{1}$ & \\
\hline architecture, spatial planning, $\mathrm{FH}$ & 86 & $.87^{2}$ & \\
\hline construction engineering, application, $\mathrm{FH}$ & 153 & $.86^{2}$ & \\
\hline electrical engineering, $\mathbf{F H}$ & 217 & $.82^{1}$ & \\
\hline mechanical engineering, FH & 421 & $.86^{2}$ & \\
\hline industrial engineering, $\mathrm{FH}$ & 51 & $.92^{2}$ & \\
\hline computer sciences etc., FH & 80 & $.77^{1}$ & \\
\hline economics, FH & 211 & $.54^{1}$ & \\
\hline social work, FH & 211 & $.94^{2}$ & \\
\hline others $^{1}, \mathrm{FH}$ & 54 & $.91^{2}$ & \\
\hline agricultural economics, nutritional science, university & 59 & $.53^{1}$ & \\
\hline architecture, spatial planning, university & 60 & $.85^{2}$ & \\
\hline construction engineering, application, university & 77 & $.79^{1}$ & \\
\hline electrical engineering, university & 153 & $.95^{2}$ & \\
\hline mechanical engineering, university & 294 & $.94^{2}$ & \\
\hline industrial engineering, university & 108 & $.97^{2}$ & \\
\hline physics, university & 171 & $.32^{1}$ & \\
\hline biology, university & 64 & $.33^{1}$ & \\
\hline chemistry, university & 113 & $.52^{1}$ & \\
\hline pharmaceutics, university & 56 & $.95^{2}$ & $\mathbf{X}$ \\
\hline mathematics, university & 100 & $.19^{1}$ & \\
\hline computer sciences, university & 146 & $.49^{1}$ & \\
\hline human medicine, university & 242 & $.97^{2}$ & $\mathbf{X}$ \\
\hline psychology, university & 88 & $.98^{2}$ & \\
\hline education science, university & 95 & $.88^{2}$ & \\
\hline linguistics, cultural studies, university & 67 & $.67^{1}$ & \\
\hline law, university & 286 & $.94^{2}$ & $\mathbf{X}$ \\
\hline economics, university & 600 & $.28^{1}$ & \\
\hline $\begin{array}{l}\text { teaching degree for elementary school, university (of } \\
\text { education) }\end{array}$ & 330 & $.99^{2}$ & $\mathbf{X}$ \\
\hline $\begin{array}{l}\text { teaching degree for lower secondary school, university } \\
\text { (of education) }\end{array}$ & 80 & $.94^{2}$ & $\mathbf{X}$ \\
\hline $\begin{array}{l}\text { teaching degree for upper secondary school, university } \\
\text { (of education) }\end{array}$ & 302 & $.94^{2}$ & $\mathbf{X}$ \\
\hline "Magister" (liberal arts degree), university & 386 & $.18^{1}$ & \\
\hline protestant theology, university & 3 & $.00^{2}$ & $\mathbf{X}$ \\
\hline catholic theology, university & 2 & $1.00^{2}$ & $\mathbf{X}$ \\
\hline arts, university & 71 & $.20^{1}$ & \\
\hline social sciences, university & 61 & $.13^{1}$ & \\
\hline geosciences, geography, university & 101 & $.75^{1}$ & \\
\hline dentistry, university, university & 32 & $.50^{2}$ & $\mathbf{X}$ \\
\hline veterinary medicine, university & 121 & $1.00^{2}$ & $\mathbf{X}$ \\
\hline
\end{tabular}

Notes: ${ }^{*} \mathrm{FH} \triangleq$ Fachhochschule (university of applied sciences); the fields of study in bold letters are included in the analyses; ${ }^{1}$ others refer to protestant/catholic theology, arts and librarianship 
Table 2: Assignment model: propensity of having a mandatory internship

field of study (ref.: linguistics, cultural studies, university)

agricultural economics, nutritional science, $\mathrm{FH}^{1}$

0.564

electrical engineering, $\mathrm{FH}$

$1.244^{* *}$

computer sciences etc., $\mathrm{FH}$

0.725

economics, $\mathrm{FH}$

$-0.065$

agricultural economics, nutritional science, university

$0.990^{*}$

construction engineering, application, university

$-3.751^{* *}$

physics, university

$-1.537^{* *}$

biology, university

$-3.675^{* *}$

chemistry, university

$-1.717^{* * *}$

mathematics, university

$-0.926$

computer sciences, university

$-0.217$

economics, university

$-0.867$

"Magister", university

$-2.195^{* *}$

geosciences, geography, university

0.781

social sciences, university

$-2.465^{* * *}$

arts, university

federal state of attended post-secondary institution (1: West Germany, 0: GDR)

$-1.956^{* *}$

$-1.290^{* * *}$

interaction terms of federal state and field of study

west $*$ physics, university

$2.624^{*}$

west * chemistry, university

$3.540^{* *}$

$-1.426^{* * *}$

west * economics, university

0.485

*

$-0.411$

type of eligibility to university (Abitur) ${ }^{2}$ (ref.: abroad)

for all tertiary institutions

$-0.562$

solely for Fachhochschulen (university of applied sciences)

$-0.555$

federal state in which Abitur is acquired (ref.: North Germany)

North Rhine-Westphalia

$-0.611^{* * *}$

Hesse/Rhineland-Palatinate

$-0.499^{* *}$

Baden-Württemberg

0.056

Bavaria

$-0.009$

East Germany

0.024

City federal states

$0.827^{* *}$

abroad

$-0.423$

not stated

0.155

educational path to Abitur (ref.: other educational paths)

general upper secondary school (Gymnasium)

$-0.452$

vocational school

0.256

comprehensive school

$-1.124$

Abitur in GDR

$-0.212$

0.238

evening schoo

$-0.175$

specialized secondary school

$-0.947^{*}$

differing vocational types

$-0.008$

respondents' assessment of the study program

degree of structuring (ref.: very good)

good

medium

$-0.426$

poor

$-0.257$

very poor

$-0.260$

time coordination of courses (ref.: very good)

good

0.138

medium

0.060

poor

0.285

very poor

0.403

how up-to-date the acquired methods are (ref.: very good)

good

medium 
poor

how up-to-date the imparted research knowledge is (ref.: very good)

good

medium

0.039

poor

0.073

very poor

$-0.050$

opportunity for professional specialization (ref.: very good)

good

$-0.064$

medium

$-0.064$

poor

$-0.060$

very poor

$-0.008$

contact to teaching staff (ref.: very poor)

very good

$-0.585$

good

$-0.404$

medium

$-0.311$

poor

$-0.398$

counseling and support (ref.: very good)

good

0.100

medium

$-0.022$

poor

0.002

very poor

$-0.811^{*}$

discussion of exams and papers (ref.: very good)

good

0.284

medium

0.325

poor

0.236

very poor

0.213

availability of literature in library (ref.: very poor)

0.083

very good

$-0.061$

good

0.216

0.154

access to computer system and personnel (ref.: very poor)

very good

0.137

good

0.109

medium

0.303

poor

0.095

use of electronic means of communication (ref.: very poor)

very good

$0.687^{*}$

good

$0.560^{*}$

medium

0.173

poor

0.190

respondents' assessment of the importance of labour market perspectives

(ref.: very unimportant)

very importan

0.392

important

$-0.012$

medium importance $\quad-0.002$

unimportant

$-0.153$

individual characteristics

year of eligibility to university $\quad 0.085$

age -0.133

square age $\quad 0.004$

age at enrollment $\quad-0.097$

$\begin{array}{lr}\text { Abitur } \text { grade } & 0.016\end{array}$

female $\quad 0.215$

parents with academic degree $\quad 0.046$

$\mathrm{N}$

2226

Pseudo-R ${ }^{2}$

0.2799

Notes: the exemplary assignment model is one out of nine and refers to all cases and the outcome job search duration; all reference categories are set arbitrary, as the interpretation of the assignment model is not the main purpose of this article. 
${ }^{1} \mathrm{FH} \triangleq$ Fachhochschulen (university of applied sciences);

${ }^{2}$ Abitur $\triangleq$ upper secondary school degree, equivalent to A-levels; data source: HIS graduate panel, own calculations

${ }^{*} p<0,05 ;{ }^{* *} p<0,01 ;{ }^{* * *} p<0,001$ (two-tailed tests) 
Table 3: The ATT of mandatory internships on the transition from higher education to work

\begin{tabular}{|c|c|c|c|}
\hline & search time & $\begin{array}{l}\text { employment history } \\
\text { complexity }\end{array}$ & log hourly wages \\
\hline \multicolumn{4}{|l|}{ all cases } \\
\hline unmatched (t-value) & $-1.398(-3.43)$ & $-0.206(-2.77)$ & $-0.054(-3.02)$ \\
\hline ATT [z-value $]$ & $-0.027[-0.06]$ & $-0.091[-0.79]$ & $-0.039[-1.58]$ \\
\hline number of obs. & 2226 & 2225 & 1971 \\
\hline off common support ${ }^{1}$ & 43 & 43 & 39 \\
\hline \multicolumn{4}{|l|}{$\begin{array}{l}\text { parents with } \\
\text { academic degree }\end{array}$} \\
\hline unmatched (t-value) & $-1.329(-2.11)$ & $-0.061 \quad(-0.52)$ & $-0.047(-1.59)$ \\
\hline ATT [z-value $]$ & $0.245[0.29]$ & $0.162[1.03]$ & $0.006[0.14]$ \\
\hline number of obs. & 997 & 996 & 887 \\
\hline off common support & 74 & 73 & 46 \\
\hline \multicolumn{4}{|l|}{$\begin{array}{l}\text { parents without } \\
\text { academic degree }\end{array}$} \\
\hline unmatched (t-value) & $-1.435(-2.68)$ & $-0.308(-3.26)$ & $-0.066(-2.99)$ \\
\hline ATT [z-value] & $-0.262[-0.38]$ & $-0.087[-0.57]$ & $-0.063[-1.82]$ \\
\hline number of obs. & 1224 & 1224 & 1079 \\
\hline off common support & 25 & 25 & 40 \\
\hline
\end{tabular}

Notes: kernel matching with Epanechnikov kernel, bandwidth $\mathrm{h}=0.06$; $\mathrm{t}$-statistics of unmatched results in parentheses; z-values derived from bootstrap-standard errors of ATT in brackets ( $\mathrm{N}=500$ replications); data source: HIS graduate panel, own calculations

1 "off common support" are those cases which have to be excluded from the analysis because a no case with a similar propensity to be in a program with mandatory internships could be found, according to our assignment model. In our analysis, the number of these cases can be considered as being small. 